\title{
Physician seeks inquiry into ordeal
}

A ccording to its own bylaws, Capital Health in Halifax, Nova Scotia, had 40 days to address allegations that treatment approaches used by oncologist Dr. Michael Goodyear in 2002 were endangering patients.

Nearly seven years later, the district health authority's own board of directors determined those allegations were, in fact, baseless. In the meantime, Goodyear is virtually broke. His house is in the hands of a bankruptcy trustee. He is no longer licensed to practice medicine in the province of Nova Scotia and is asking the provincial government to convene a public inquiry into the case.

Observers suggest the sad tale might easily have been avoided had the regional health authority adopted a few modern management practices, demonstrated a bit more political savvy.

The root of the problem - disagreements with those further up the hospital hierarchy — is entirely common, says James Turk, executive director of the Canadian Association of University Teachers. "In terms of the problems that generated this, unfortunately, they're all too typical. This is what would be called 'office politics' in other contexts."

In hospitals, a lack of perceived deference is not well tolerated, says Arthur Schafer, director of the Centre for Professional and Applied Ethics at the University of Manitoba in Winnipeg. "Any person who speaks out critically is viewed as a threat at best and someone to be crushed at worst. It's a clash between the culture that requires every level but the top to kowtow."

Moreover, it's not uncommon that dispute settlement mechanisms prove inadequate or that time limits for resolving a conflict are ignored, says Jocelyn Downie, Canada Research Chair in health law and policy at Dalhousie University in Halifax.

"There's a clear lack of a grievance process in the institutions. These things just drag on," she says.

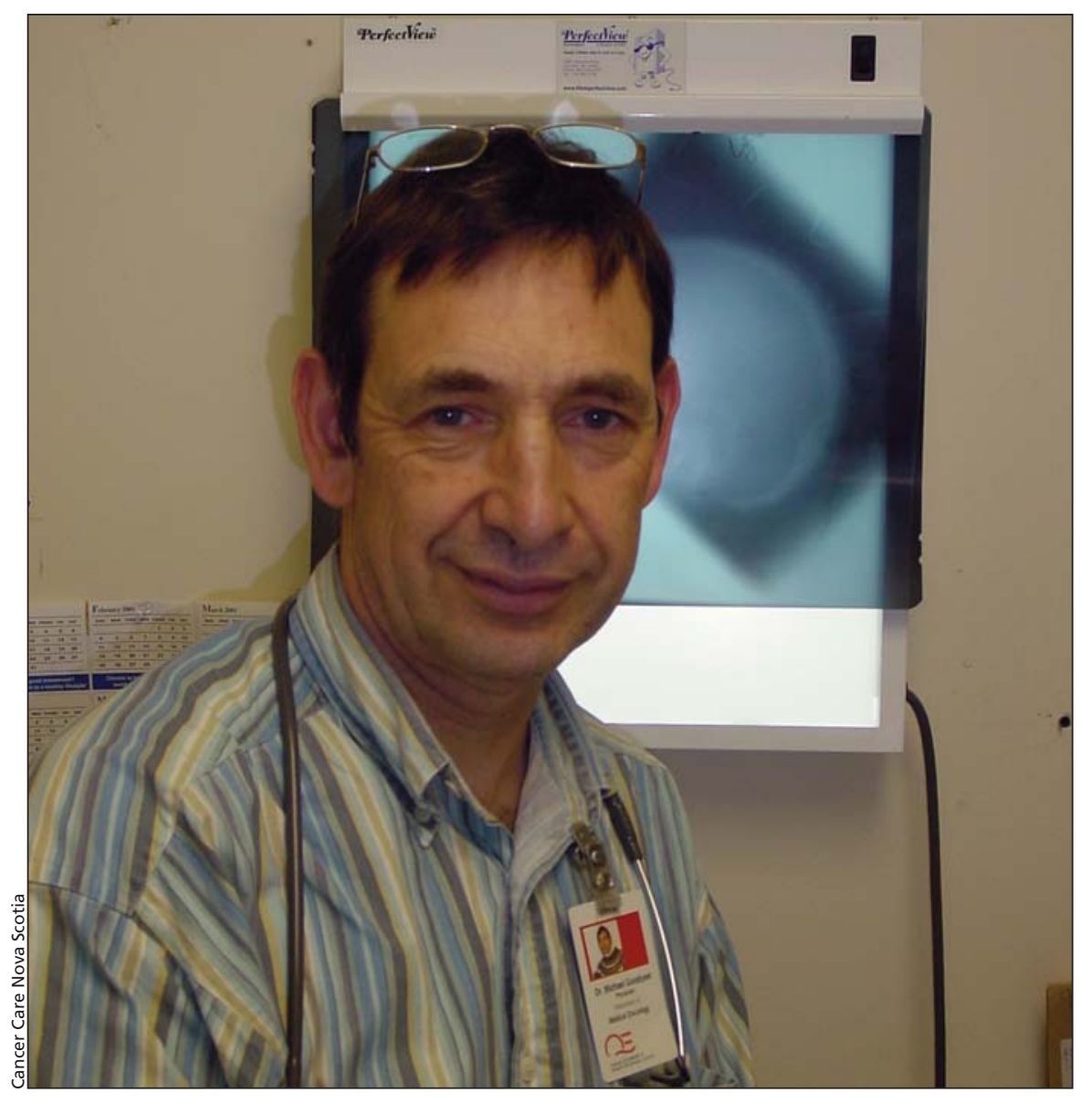

After a seven-year ordeal, oncologist Dr. Michael Goodyear awaits an apology.

In Goodyear's case, along with that of colleague and cardiologist Dr. Gabrielle Horne - who is now suing Capital Health for having groundlessly suspended her for four years — no such dispute settlement processes were in place. The health authority has since given the hospital's chief executive officer the right to step in and resolve such disputes, while the provincial government mandated changes to the Medical Staff Disciplinary bylaws in 2007.

"Some changes that were intended to streamline the disciplinary process included creating subcommittees so that not all members of a large committee had to sit on a matter, and streamlining roles of committees so that hearings were not required at every stage in the process," notes Valerie Belle- fontaine, the department's director of communications.

The upshot is that "dispute resolution is back. It's a mandatory step," notes Dr. Ross Leighton, president of Doctors Nova Scotia.

All of which was of little benefit to Goodyear when his ordeal began in 2002. And even if it had been, Goodyear is not convinced that the recent changes would have been of assistance, as he says the reconstructive surgery does not go far or deep enough.

"I don't believe, for a minute, things have changed," the Dalhousie assistant professor says. "I think the whole system needs to be revamped using proper principles of industrial psychology and conflict resolution."

A public inquiry is necessary, 
Goodyear adds. "The taxpayer is entitled to know what happened and why it happened - and more importantly what should happen in the future. This type of thing can't go on."

Leighton concurs. "When all this is over, it's never a bad idea to take a look at all the steps," says the professor of surgery at Dalhousie University and a member of the surgical staff at the QEII Health Sciences Centre, which is part of Capital Health.

Indeed, he adds, it may be necessary for physician recruitment and retention in the province. "[We need to] take steps to show we're working to address this so that people who come to Nova Scotia will feel they will be fairly treated."

Others aren't convinced. "I'm more inclined ... to say we know what the problem is; I'd rather we say to Dalhousie and the Capital District Health Authority: 'fix it'," says Downie, a professor in the faculties of law and medicine at Dalhousie.

Downie adds that the faculty of medicine has already sent that message to the university's senior management. Several years ago, as Goodyear's career unravelled and the only action taken was repeated inaction, a special recommendation from faculty was put forward that outlined a process the university should put in place to prevent similar situations from occurring.

The lack of a response to that recommendation is deafening, says Downie. "There's a block somewhere. There are too many years [elapsed] for it to be just the slowness of bureaucracy."

Goodyear's call for an inquiry is unlikely to succeed, as Bellefontaine indicated that the provincial government isn't inclined to initiate such an investigation. "They can be very long, expensive processes that may not necessarily result in solutions to this situation."

Still unresolved is whether disciplinary action should be taken against the physicians who levied the unjust allegations and allowed the delays to continue.

"These people are very seldom held to account," says Schafer. "The problem is not with accusations, but [with] those that are unfounded and malicious. When those are made, the people who made them should be held accountable."

In Goodyear's case, that seems altogether unlikely, especially as, in its 46page report, a review panel put in place by health authority's board of directors applauded the actions of the District
Medical Advisory Committee, one of the committees at the centre of the controversy. "The Board has had the benefit of hearing additional evidence and all evidence it heard was subject to cross-examination," the report stated. "It believes where that where it has reached conclusions that differ from those reached by the DMAC, it is most likely because the Board received and considered more evidence and that the evidence was subject to a more rigorous review."

Capital Health officials did not make themselves available for an interview.

Goodyear, meanwhile, is left fighting to get his privileges restored, in a battleground now littered with more legal briefs than acrimony. As a suspended physician, Goodyear was forbidden from undertaking continuing medical education and thus can't practice because he's been without training for three years.

Goodyear also waits for a final indication his ordeal has come to an end: an apology. - donalee Moulton, Halifax, NS

DOI:10.1503/cmaj.109-3004 